\title{
The national food and nutrition strategy for the Portuguese COVID-19 response
}

\author{
Maria João Gregório $\mathbb{1}^{1,2} \cdot$ Susana Irving ${ }^{3}$ Diana Teixeira ${ }^{1,4,5} \cdot$ Graça Ferro $^{6} \cdot$ Pedro Graça $^{1,2} \cdot$ Graça Freitas $^{7}$
}

Received: 9 June 2020 / Revised: 2 October 2020 / Accepted: 15 November 2020 / Published online: 14 January 2021

(c) Springer Nature Limited 2020

\section{To the Editor:}

Nutrition has been increasingly recognized as a relevant area in the context of the COVID-19 pandemic and it has been reported that the double burden of malnutrition, i.e., undernutrition and obesity, seems a risk factor for severe illness in SARS-CoV-2 infection [1]. In addition, the widespread implementation of public health safeguarding measures combined with social restrictions, have increased the challenges facing healthy eating [2].

In this context, we welcomed the call for action by Naja and Hamadeh published in April in this journal [3]. In that perspective, the authors, supported by an adapted ecological model of health behavior, introduce a conceptual framework to maintain optimal nutrition at different levels, such as individual, community, national and even, global. In this brief comment, we present a food and nutrition nationwide strategy $[4,5]$ developed by the National Program for Healthy Eating Promotion (PNPAS-DGS) of Portugal's Directorate-General of Health (DGS), which is also based on a multilevel framework (Fig. 1). Likewise, intended to be

Maria João Gregório

mariajoaobg@dgs.min-saude.pt

1 National Program for Healthy Eating Promotion (PNPAS), Directorate-General of Health (DGS), Lisbon, Portugal

2 Faculty of Nutrition and Food Sciences, University of Porto, Porto, Portugal

3 Nutrition Translational Research, London, UK

4 Nutrition and Metabolism, Faculdade de Ciências Médicas I NOVA Medical School, Universidade NOVA de Lisboa, Lisboa, Portugal

5 Comprehensive Health Research Centre (CHRC), Universidade Nova de Lisboa, Lisboa, Portugal

6 Unidade Local de Saúde do Alto Minho, E.P.E, Viana do Castelo, Portugal

7 Directorate-General of Health (DGS), Lisbon, Portugal an opportunity to establish a call to action by providing pertinent and pragmatic guidance coupled with informative materials made available throughout the concerted Portuguese response to the COVID-19 pandemic. When comparing to other neighboring countries, the epidemiological context of COVID-19 in Portugal seems to have benefited from several factors. Among others, the geographical location which might have allowed more preparation time, the effectiveness of the mitigation measures implemented by the Government and Health Authorities and its compliance by the population, could explain the current outlook. Even though, following the identification of the immediate concerns of an ever evolving pandemic scenario and to enable action, under unprecedented public health circumstances, the PNPAS proposed a three level framework. Firstly, at a general level, an attempt was made to tackle the short and long-term nutritional consequences of COVID-19 population-based issues. As the short-term nutritional consequences, the possible impact of lockdown and social distancing/shielding on food choices and eating patterns was identified, and as such, suitable dietary recommendations and food safety advice were issued. Moreover, throughout social media, there seemed to be an alarmist torrent of both the perceived threat posed by SARS-CoV-2 food transmission, alongside reports on the potential role of certain foods or supplements to prevent or treat infection. Hence, awareness campaigns were deployed to fight nutrition-related misinformation and to clarify the evidence behind emergent nutritional putative associations concerning COVID-19 [6, 7]. Regarding the long-term consequences, the COVID-19 crisis economic burden and the rise of food insecurity was anticipated. Preliminary data from a very recent evaluation of food insecurity during the COVID-19 lockdown period, in Portugal, showed a prevalence of $33.2 \%$ [8]. For this reason, a food insecurity screening was set up, together with the National Health Service primary healthcare settings, followed by the development of interventional models to be implemented for at-risk individuals or families. Meanwhile, a nationwide 

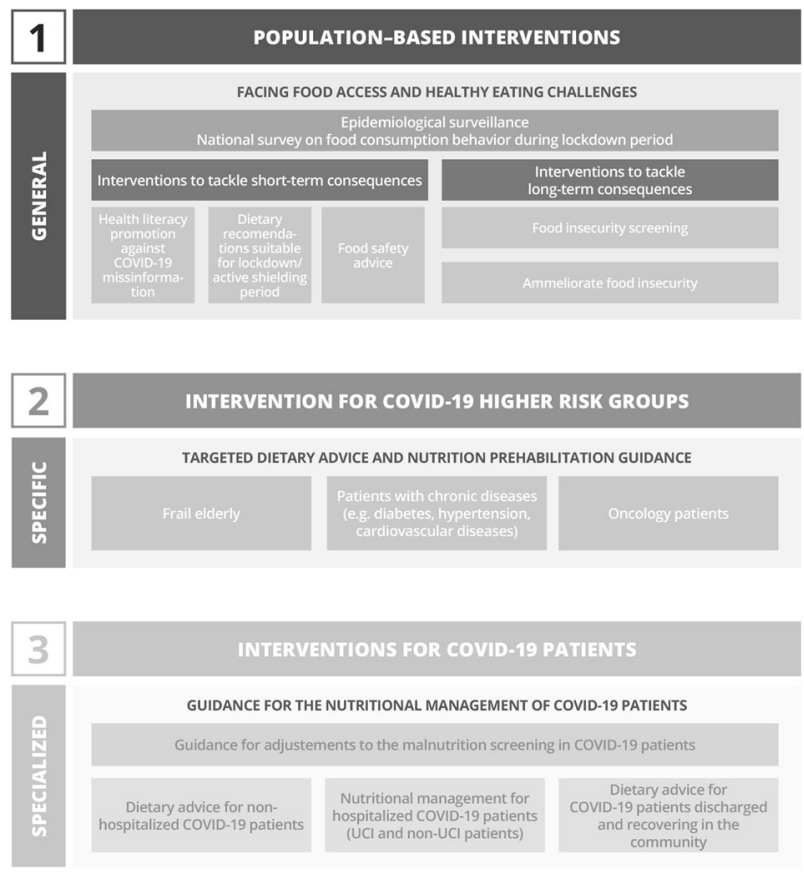

Fig. 1 National framework regarding food and nutrition during the COVID-19 pandemic response. Three-tier framework for a call to action regarding dietary and nutritional interventions established during the concerted Portuguese COVID-19 response: general, specific and specialized.

survey on COVID-19 impact concerning on food insecurity, eating habits and heath literacy was conducted and results have already been made public. These will further inform future strategies and interventions [8].

A second specific level was set to bring forth opportunities to optimize food intake, nutritional status, and metabolic health for some of the most vulnerable to severe disease in the event of falling sick with COVID-19, i.e., the frail elderly and those with high risk chronic conditions, like metabolic disorders (e.g., diabetes) or cancer. The proposed approach for this level of intervention took its lead both from nutrition prehabilitation and "teachable moment" strategies $[9,10]$. To help facilitate timely and pertinent community level interventions, COVID-19- specific guidelines were developed to optimize elderly nutritional status. Furthermore, patients with chronic diseases (e.g., diabetes, hypertension, and cardiovascular disease) should be considered as a main target, by primary care settings, for a brief counseling intervention model to encourage healthy eating to further health gains. If we consider the COVID-19 disruption to routine healthcare provision, the establishment of food and nutrition strategies that may support the ongoing communication and care of patients with noncommunicable diseases becomes extremely important. Knowing this, and for all those that may be impacted the most, such as cancer patients, an interdisciplinary effort recognizing the importance of a systematic, early and tightly integrated malnutrition screening and subsequent specialized management, should also be reinforced throughout the national health system.

Lastly, the third specialized level, comprising guidance and indications for nutritional support throughout the COVID-19 care pathway, whether it be dietary advice for symptom management, for the great majority, that will be self-managing their disease at home; or the best-practice, for timely and safe nutritional support, for the few that will be hospitalized while fighting COVID-19. For these patients, either severe in the ward or critical in the ICU, a duly adjusted nutritional risk screening and tailored nutrition support must remain as an integral part of their standard of care. Plus, it has been reinforced that the stand-alone advice, and common thread to each and every treatment setting, is that an adequate and nutritious diet, when possible, is essential in aiding recovery, especially after the current rigours of a hospital stay.

In conclusion, the opportunities for nutrition interventions in times of COVID-19 are endless. Considering the implementation of a food and nutrition national strategy, together with decisive and concerted action, must be encouraged in order to mitigate the widespread pernicious consequences of the COVID-19 crisis on population dietary behavior/habits, to support an adequate nutritional status in at-risk groups and to ensure appropriate nutritional support for COVID-19 patients.

Acknowledgements The authors would like to thank Dr. Luísa Trindade, Dr. Paula Alves, and many other colleagues for all their dedication and insights from the frontline.

\section{Compliance with ethical standards}

Conflict of interest The authors declare that they have no conflict of interest.

Publisher's note Springer Nature remains neutral with regard to jurisdictional claims in published maps and institutional affiliations.

\section{References}

1. Barazzoni R, Bischoff SC, Breda J, Wickramasinghe K, Krznaric $Z$, Nitzan D, et al. ESPEN expert statements and practical guidance for nutritional management of individuals with SARS-CoV2 infection. Clin Nutr. 2020;39:1631-8.

2. Muscogiuri G, Barrea L, Savastano S, Colao A. Nutritional recommendations for CoVID-19 quarantine. Eur J Clin Nutr. 2020;74:850-1.

3. Naja F, Hamadeh R. Nutrition amid the COVID-19 pandemic: a multi-level framework for action. Eur $\mathrm{J}$ Clin Nutr. 2020;74:1117-21.

4. Gregório MJ, Irving S, Teixeira D, Sousa SMD, Ferreira B, Figueira I, et al. Manual de Intervenção Alimentar e Nutricional na COVID-19 Lisbon: Direção-Geral da Saúde. 2020. https:// nutrimento.pt/activeapp/wp-content/uploads/2020/05/Manual-de- 
intervenc\%CC\%A7a\%CC\%83o-Alimentar-e-nutricional-covid19.pdf.

5. Programa Nacional para a Promoção da Alimentação Saudável. COVID-19-Documentos para descarregar Lisbon: Direção-Geral da Saúde. 2020. https://alimentacaosaudavel.dgs.pt/documentospara-descarregar/.

6. Programa Nacional para a Promoção da Alimentação Saudável. O SARS-CoV-2 (coronavírus) pode ser transmitido através dos alimentos? Lisbon: Direção-Geral da Saúde. 2020. https:// nutrimento.pt/noticias/o-sars-cov-2-coronavirus-pode-ser-tra nsmitido-atraves-dos-alimentos/.

7. Programa Nacional para a Promoção da Alimentação Saudável. Podemos reforçar o sistema imunitário através da alimentação?
Lisbon: Direção-Geral da Saúde. 2020. https://nutrimento.pt/ noticias/podemos-reforcar-o-sistema-imunitario-atraves-da-a limentacao/.

8. Direção-Geral da Saúde. REACT-COVID-Inquérito sobre Alimentação e Atividade Física em contexto de contenção social. Lisbon: Direção-Geral da Saúde. 2020. https://nutrimento.pt/a ctiveapp/wp-content/uploads/2020/06/React_covid_ inqueritosobrealimentacaoeatividadefisicaemcontextoconteca osocial.pdf.

9. Silver JK. Prehabilitation could save lives in a pandemic. BMJ Opin. 2020;369:m1386.

10. Lawson PJ, Flocke SA. Teachable moments for health behavior change: a concept analysis. Patient Educ Couns. 2009;76:25-30. 